Review

\title{
Haloarchaea and the Formation of Gas Vesicles
}

\section{Felicitas Pfeifer}

Microbiology and Archaea, Department of Biology, Technische Universität Darmstadt, Schnittspahnstrasse 10, 64287 Darmstadt, Germany; E-Mail: pfeifer@bio.tu-darmstadt.de; Tel.: +49-6151-1623670; Fax: +49-6151-1623672

Academic Editors: Hans-Peter Klenk, Michael W. W. Adams and Roger A. Garrett

Received: 15 December 2014 / Accepted: 26 January 2015 / Published: 2 February 2015

\begin{abstract}
Halophilic Archaea (Haloarchaea) thrive in salterns containing sodium chloride concentrations up to saturation. Many Haloarchaea possess genes encoding gas vesicles, but only a few species, such as Halobacterium salinarum and Haloferax mediterranei, produce these gas-filled, proteinaceous nanocompartments. Gas vesicles increase the buoyancy of cells and enable them to migrate vertically in the water body to regions with optimal conditions. Their synthesis depends on environmental factors, such as light, oxygen supply, temperature and salt concentration. Fourteen gas vesicle protein $(g v p)$ genes are involved in their formation, and regulation of $g v p$ gene expression occurs at the level of transcription, including the two regulatory proteins, GvpD and GvpE, but also at the level of translation. The gas vesicle wall is solely formed of proteins with the two major components, GvpA and $\mathrm{GvpC}$, and seven additional accessory proteins are also involved. Except for GvpI and GvpH, all of these are required to form the gas permeable wall. The applications of gas vesicles include their use as an antigen presenter for viral or pathogen proteins, but also as a stable ultrasonic reporter for biomedical purposes.
\end{abstract}

Keywords: halophilic Archaea; gas vesicle formation; gene regulation

\section{Introduction}

The moderately to extremely halophilic Archaea (Haloarchaea) are adapted to salty environments with sodium chloride concentrations ranging from $1 \mathrm{M}$ up to saturation at 5.3 $\mathrm{M}$. They are heterotrophic, often facultatively anaerobic microorganisms living on amino acids. Bioinformatic analyses of 10 
haloarchaeal and more than 1000 bacterial reference genomes imply that a common haloarchaeal ancestor, the "founder" haloarchaeon, evolved from an anaerobic methanogen by acquiring 1047 bacterial genes, thus expanding the physiological properties to an aerobic organotroph [1]. The transferred genes mainly derive from Actinobacteria and are responsible for catabolic metabolism, membrane transporters and components required for oxygen respiration [1,2]. Lateral gene transfer is still a special feature of the Haloarchaea, but their aerobic lifestyle appears to be a consequence of a single mass acquisition of bacterial genes.

The first haloarchaeon characterized in the laboratory was Halobacterium (Hbt.) salinarum (formerly Hbt. halobium), isolated as a contaminant from salted fish in 1919 [3]. All other Haloarchaea derive from salt lakes, salt flats or solar salterns. Hbt. salinarum uses light-driven ion pumps (proton pump: bacteriorhodopsin; chloride pump: halorhodopsin; plus sensory rhodopsins) as special energy conversion and sensing systems, and similar light-driven proton pumps are also present in marine proteobacteria [4,5]. Bacteriorhodopsin is produced under microaerobic conditions and forms almost crystalline purple patches in the cytoplasmic membrane of Hbt. salinarum (purple membrane, Pum). Haloarchaea also contain C50 carotenoids (bacterioruberins, Rub) leading to red colonies on agar plates. The possession of gas vesicles ( $\mathrm{Vac}$ ) turns the colony color into pink and opaque, as opposed to the red transparent colonies of $\mathrm{Vac}^{-}$mutants (Figure 1a). Blooms and biofilms of Haloarchaea color brines and salt lakes red, as also seen for solar salterns at the coastline. Since Haloarchaea captured in salt crystals survive for a very long time, the use of natural sea salt was the reason why Hbt. salinarum grew on salted fish.
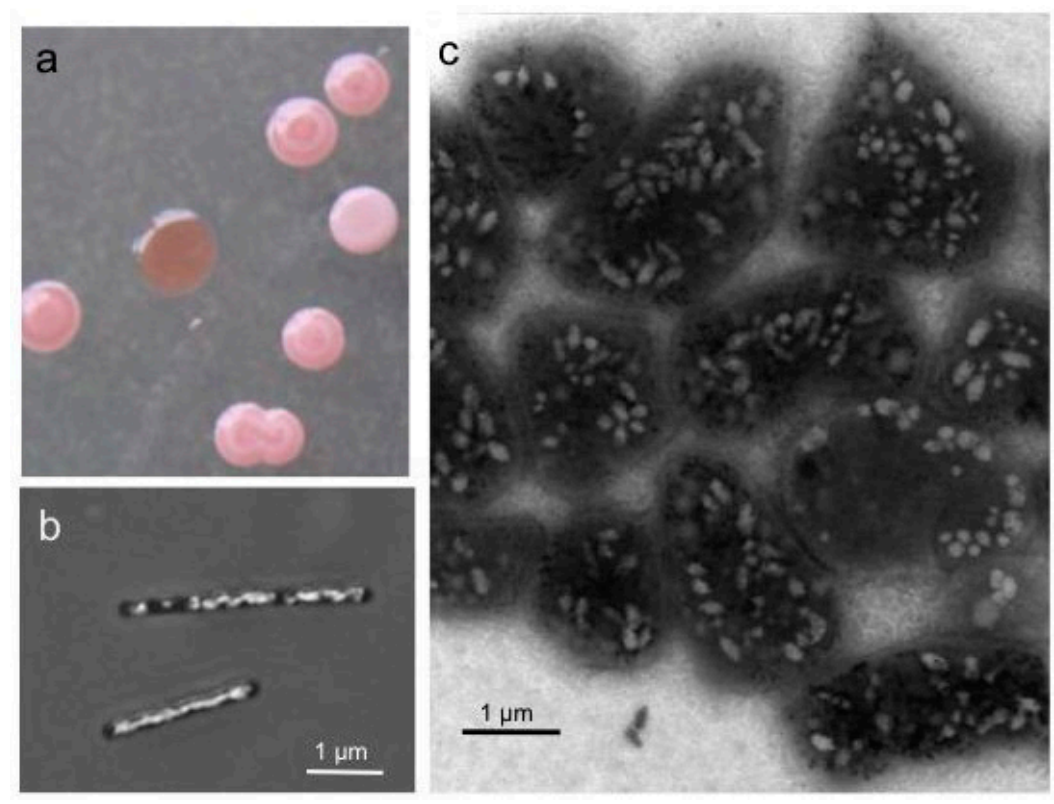

Figure 1. Colonies (a) and cells of Halobacterium (Hbt.) salinarum producing gas vesicles (b,c). (a) Colonies on solid media grown for one week at $40{ }^{\circ} \mathrm{C}$ and three weeks at room temperature. Vesicle $\left(\mathrm{Vac}^{+}\right)$cells form pink white colonies, whereas colonies of $\mathrm{Vac}^{-}$ mutants are red and transparent. (b) Cells grown in liquid media observed by phase-contrast light microscopy. (c) Cells of a $\mathrm{Vac}^{+}$colony investigated by transmission electron microscopy. The pleomorphic shape of the cells grown for three months on solid media differs from the rod-shaped cells seen in liquid culture. 
Hbt. salinarum, Haloferax (Hfx.) mediterranei, Halorubrum vacuolatum and Haloquadratum (Hqr.) walsbyi contain up to 70 spindle- or cylinder-shaped gas vesicles per cell, easily seen as white bodies by phase-contrast light microscopy or transmission electron microscopy (Figure 1b,c). Fourteen gvp genes clustered in the genomic vac region are involved in gas vesicle formation in Hbt. salinarum and Hfx. mediterranei [6], whereas only 12 gvp genes (gvpDE are lacking) are found in the $\mathrm{Vac}^{+}$species Hrr. vacuolatum and Hqr. walsbyi [7-9]. In contrast, Halopiger xanaduensis, Haladaptatus pauchihalophilus and the haloalkaliphiles, Natrinema pellirubrum, Natrialba magadii and Natronobacterium gregoryi, all contain a vac region lacking $g v p C$ and $g v p D E$ [10]. These 11 gvp genes are sufficient for gas vesicle genesis, but these species are all $\mathrm{Vac}^{-}$. It is not known whether their gvp gene clusters are generally not expressed or only transcribed under special conditions.

The vac regions have been characterized for the Hbt. salinarum strains PHH1, NRC-1, SB3, GN101 and GRB [6,11-13]. The latter three strains are more recent natural isolates and genetically stable, whereas PHH1 (DSM 670) and NRC-1 (ATC 700922) are derived from strain collections and exhibit high mutation rates of Vac, Rub and Pum, due to the action of insertion (ISH) elements. The vac regions of PHH1 and NRC-1 were identified using the gvpA gene probe of the cyanobacterium, Calothrix [11,14]. This gene encodes the major gas vesicle structural protein, GvpA, and is highly conserved between bacterial and archaeal gas vesicle producers. Transformation experiments using the $\mathrm{Vac}^{-}$species, $H f x$. volcanii, uncovered that $g v p A$ is not sufficient for gas vesicle formation and that 12 additional gvp genes are required [13,15]. Furthermore, $\mathrm{Vac}^{-}$mutants of PHH1 (and $\mathrm{NRC}-1$ ) are usually due to the integration of an ISH-element in a 9-kbp region surrounding gvp $A$ [13]. The $\mathrm{Vac}^{-}$mutant strain, $\mathrm{R} 1$, whose genome sequence has been determined by the Oesterhelt Lab, incurred an ISH3 insertion upstream of p-gvpA, preventing the transcription [16]. Hbt. salinarum PHH1, R1 and NRC-1 all contain two different gvp gene clusters, p-vac ( $g v p 1$ in NRC-1) and c-vac ( $g v p 2$ in NRC-1), whereas SB3, GN101 and GRB contain the c-vac region only $[6,12,17]$. Expression of p-vac leads to spindle-shaped gas vesicles throughout growth, whereas the cylinder-shaped c-vac gas vesicles occur in the stationary growth phase only. The p-vac region is located on a plasmid and often incurs an ISH element. The 14 gvp genes constituting each vac region are arranged in the two oppositely oriented gene clusters, gvpACNO and gvpDEFGHIJKLM (Figure 2a). This arrangement is typical for $\mathrm{p}$-vac and c-vac, but also for the mc-vac region of $H f x$. mediterranei [6]. Hfx. mediterranei produces cylinder-shaped gas vesicles in the stationary growth phase when grown in $25 \%$ salt-media [18]. In contrast, twelve gvp genes in Hrr. vacuolatum and Hqr. walsbyi are arranged as the gvpACNO-FGHIJKLM gene cluster with additional DNA inserted between $g v p O$ and $g v p F$ in Hqr. walsbyi.

In this review, I will discuss the expression of the vac regions in Hbt. salinarum and Hfx. mediterranei, with emphasis on the regulation at the transcriptional and translational level. In addition, experiments to deduce the early steps in the formation of the gas vesicle wall will be presented. Furthermore, I will discuss the applications of gas vesicles in biotechnology and biomedicine.

\section{Differences Between the Hbt. salinarum Strains and the Action of ISH Elements}

Hbt. salinarum PHH1, R1 and NRC-1 are very closely related, but differ in the arrangement of their plasmids, due to the frequent action of various ISH elements. The nucleotide sequences determined for the chromosomes of NRC-1 and strain R1 differ by twelve point mutations only, but the plasmid 
sequences are completely rearranged [16]. All three strains contain many ISH-elements, first observed with Vac, Rub or Pum mutants [19,20]. A 1\% mutation frequency is found with Vac, but also mutants in Rub or Pum occur at frequencies of $10^{-4}$ [19]. Rub and Pum are chromosomally encoded, but mutants of these phenotypes always carry insertions in the respective gene regions and also incurred additional alterations in the plasmid DNA, including insertions, duplications, inversions and/or deletions [19,21]. Hbt. salinarum NRC-1 contains the gvpl gene cluster on the 190-kbp plasmid, pNRC100, whereas the almost identical p-vac region is located on plasmid pHH1 in Hbt. salinarum PHH1 or on pHS1 in strain R1 (Table 1) [6,16,22]. The gvp2 gene cluster resides on the mini-chromosome, pNRC200, in NRC-1, which contains a 145-kbp duplication of pNRC100, including a copy of $g v p 1$, whereas c-vac in R1 is located on plasmid pHS3, similar to c-vac in Hbt. salinarum PHH1 (Table 1). Gas vesicles due to the expression of c-vac are only found in Hbt. salinarum $\mathrm{PHH} 4$, which harbors the 35-kbp pHH4, a small derivative of pHH1 lacking p-vac [23,24].

Table 1. Characteristics of Hbt. salinarum strains.

\begin{tabular}{|c|c|c|c|c|}
\hline Strains & Plasmids and vac regions & Vac phenotype & Presence of $t f b$ and $t b p$ & Reference \\
\hline \multirow{2}{*}{$\begin{array}{l}\text { PHH1 } \\
\mathrm{Vac}^{+}\end{array}$} & \multirow{2}{*}{$\begin{array}{l}\text { pHH1, } 150 \mathrm{kbp} ; \\
\text { p-vac mini-chromosome *; c-vac }\end{array}$} & \multirow{2}{*}{$\begin{array}{l}\text { spindle-shaped gas vesicles } \\
\text { from p-vac in all stages of } \\
\text { growth }\end{array}$} & $t b p: A, B, C:: \mathrm{ISH}, D, E, F$ & {$[12,19]$} \\
\hline & & & $t f b: A, B, D, F, G$ & {$[25,26]$} \\
\hline \multirow[b]{2}{*}{$\begin{array}{l}\text { PHH4 } \\
\mathrm{Vac}^{+}\end{array}$} & \multirow{2}{*}{$\begin{array}{l}\mathrm{pHH} 4,35 \mathrm{kbp} \\
\text { mini-chromosome*; c-vac }\end{array}$} & \multirow{2}{*}{$\begin{array}{l}\text { cylinder-shaped gas vesicles } \\
\text { from c-vac in the stationary } \\
\text { growth phase }\end{array}$} & tbp: $E$ & {$[24,27]$} \\
\hline & & & $t f b: A, B, D, F, G$ & {$[25,26]$} \\
\hline \multirow{2}{*}{$\begin{array}{l}\mathrm{NRC}-1 \\
\mathrm{Vac}^{+}\end{array}$} & \multirow{2}{*}{$\begin{array}{l}\text { pNRC100, } 190 \mathrm{kbp} ; g v p 1 \\
\text { pNRC200, } 354 \mathrm{kbp} ; \\
\text { contains } g v p 1 \text { and } g v p 2\end{array}$} & \multirow{2}{*}{$\begin{array}{l}\text { spindle-shaped gas vesicles } \\
\text { from gvpl in all stages of } \\
\text { growth }\end{array}$} & $t b p: A, B, C, D, E, F$ & {$[22]$} \\
\hline & & & $\begin{array}{l}t f b: A, B, C, D, E, F, G \\
C+E \text { on pNRC200 }\end{array}$ & {$[22]$} \\
\hline \multirow{2}{*}{$\begin{array}{c}\mathrm{R} 1 \\
\mathrm{Vac}^{-}\end{array}$} & \multirow{2}{*}{$\begin{array}{l}\text { pHS1, } 147 \mathrm{kbp} \text {; p-vac::ISH3 } \\
\text { pHS3, } 284 \mathrm{kbp} \text {; c-vac } \\
\text { pHS2, } 195 \mathrm{kbp} \text {; pHS4, } 40 \mathrm{kbp}\end{array}$} & \multirow{2}{*}{$\begin{array}{l}\mathrm{Vac}^{-} \text {phenotype due to an } \\
\text { ISH3 insertion upstream of } \\
g v p A \text { in p-vac }\end{array}$} & $\begin{array}{l}t b p: A, B:: \mathrm{ISH}, C, D, E, \\
F:: \mathrm{ISH}\end{array}$ & {$[16]$} \\
\hline & & & $t f b: A, B, C, D, E, F, G, H$ & {$[16]$} \\
\hline
\end{tabular}

* Plasmids or mini-chromosomes in PHH1 were described as the "cccDNA population" [19].

These plasmid alterations also affect the number of genes encoding the general transcription factors, TFB and TBP (Table 1). TFB binds to the BRE sequence adjacent to the TATA-box in the archaeal promoter and recruits, together with the TATA-box binding protein TBP, the RNA polymerase for transcription initiation. Many of the $t f b$ and $t b p$ genes are plasmid-encoded in Hbt. salinarum [16,22]. Six different $t b p$ are present, but $t b p B, t b p F$ or $t b p C$ in $\mathrm{R} 1$ and $\mathrm{PHH} 1$ are inactivated by insertion elements [25] (Table 1). Strain PHH4 even lacks all of the $t b p$ genes, except for the chromosomal $t b p E$, which is the only essential tbp under standard conditions. Differences are also seen with respect to TFB (Table 1) [26]. All of these variations in $t f b$ and $t b p$ genes might explain the differences in the amount of gas vesicles in Hbt. salinarum PHH1 and NRC-1 when both are grown under non-standard conditions. A systems analysis of the expression of the seven TFBs under different conditions in Hbt. salinarum NRC-1 reveals that both the promoter and protein-coding sequences of $t f b$ are important in encoding environment-dependent regulatory programs for rapid adaptation to environmental niches [28].

The Hbt. salinarum strains, GN101, GRB and SB3, are derived from salt flats in Mexico (GN101), France (GRB) or the USA (SB3) [29]. Their 16S rRNA genes exhibit $>99 \%$ sequence identity with the 
16S rRNA gene of Hbt. salinarum PHH1 and NRC-1. All three natural isolates produce cylinder-shaped gas vesicles in late exponential growth due to the expression of c-vac, similar to Hbt. salinarum PHH4. The mutation rate with respect to the Vac phenotype is low, since all three contain much less ISH elements compared to PHH1 and NRC-1. The plasmids found here differ from each other, except for the small, multi-copy plasmids, pGN1, pHSB1, and pGRB1, which are homologous (Table 2). All three strains lack plasmids related to the $\mathrm{pHH} 1 / \mathrm{pNRC} 100 / \mathrm{pHS} 1$ family and, thus, also p-vac. The lack of the pHH1-type plasmids implies that $\mathrm{p}$-vac might be derived from a lateral gene transfer event.

Table 2. Plasmids of Hbt. salinarum GRB, SB3 and GN101.

\begin{tabular}{|c|c|c|c|}
\hline Strains & Plasmids and vac regions & Comments & Reference \\
\hline $\begin{array}{c}\mathrm{GN} 101 \\
\mathrm{Vac}^{+}\end{array}$ & $\begin{array}{l}\text { Plasmids: } 39,43 \text { and } 1.7 \mathrm{kbp} \text { (pGN1) } \\
\text { mini-chromosome; c-vac }\end{array}$ & $\begin{array}{l}\text { Plasmids not related to } \\
\mathrm{pHH} 1 / \mathrm{pNRC} 100 / \mathrm{pHS} 1 ; \\
\text { 1.7-kbp plasmids are homologous }\end{array}$ & {$[12,29]$} \\
\hline $\begin{array}{l}\mathrm{SB} 3 \\
\mathrm{Vac}^{ \pm}\end{array}$ & $\begin{array}{l}\text { Plasmids: } 34,52 \text {, and } 1.7 \mathrm{kbp} \text { (pHSB1) } \\
\text { mini-chromosome; c-vac }\end{array}$ & $\begin{array}{l}\text { Plasmids not related to } \\
\mathrm{pHH} 1 / \mathrm{pNRC} 100 / \mathrm{pHS} 1 ; \\
\text { 1.7-kbp plasmids are homologous }\end{array}$ & {$[12,29]$} \\
\hline $\begin{array}{l}\mathrm{GRB} \\
\mathrm{Vac}^{+}\end{array}$ & $\begin{array}{l}\text { Plasmids: } 35,65 \text {, and } 1.7 \mathrm{kbp} \text { (pGRB1) } \\
\text { mini-chromosome; c-vac }\end{array}$ & $\begin{array}{l}\text { Plasmids not related to } \\
\text { pHH1/pNRC100/pHS1; } \\
\text { 1.7-kbp plasmids are homologous }\end{array}$ & {$[12,29]$} \\
\hline
\end{tabular}

\section{Regulation at the Level of Transcription Involves GvpE and GvpD}

The p-vac region of Hbt. salinarum PHH1 contains the 14 gvp genes in two oppositely-arranged gene clusters, p-gvpACNO and p-gvpDEFGHIJKLM (Figure 2a). The intervening sequence between the mRNA start sites of p-gvpA and p-gvpD is 108 base pairs (bp) in size, with the TATA-BRE elements of the $P_{p A}$ and $P_{p D}$ promoters separated by $35 \mathrm{bp}$ (Figure 2b). $P_{p A}$, driving the expression of p-gvpACNO, is the strongest promoter of p-vac, due to a 70 - to 100 -fold induction by the endogenous transcriptional activator, GvpE [30]. The co-transcript contains a 20-nt 5'-untranslated region (5'-UTR), and the major 320-nt p-gvpA transcript supports the massive GvpA production required to form the gas vesicle wall, which mainly consists of GvpA (>95\%). A stem-loop structure occurs between $\mathrm{p}-g v p A$ and $\mathrm{p}-g v p C$, and read-through leads to the minor amounts of the p-gvpAC, p-gvpACN and p-gvpACNO co-transcripts. The stem-loop was thought to be a transcription terminator, but a deletion of this structure results in similarly low amounts of read-through transcripts, as with the wild-type arrangement, implying that the stem-loop stabilizes the p-gvpA mRNA, rather than being a termination signal. In case of mc-vac, the half-life of the mc-gvpA transcript is almost $90 \mathrm{~min}$, whereas the half-life of the 3-kb mc-gvpACNO transcript is $10 \mathrm{~min}$, which is significantly shorter [31]. The p-gvpC gene downstream of p- $g v p A$ encodes the second structural protein, $\mathrm{GvpC}$, which attaches to the outer surface of the gas vesicles to stabilize the gas vesicle wall. The functions of GvpN and GvpO are not yet known.

The oppositely-oriented $P_{p D}$ promoter has a weak basal activity that is 20 - to 40 -fold activated by GvpE. The resulting p-gvpDE transcript encodes the two regulatory proteins, GvpD and GvpE. The GvpE protein is one of the few transcriptional activators characterized in Archaea. It dimerizes in solution and resembles a leucine-zipper protein [32]. The GvpE-responsive elements, $\mathrm{UAS}_{\mathrm{A}}$ and $\mathrm{UAS}_{\mathrm{D}}$, occur adjacent to the respective BRE and are 20-nucleotides (nt) in size (Figure 2b). Each element consists of two 8-nt 
sequences separated by $4 \mathrm{nt}$ that are not important for the activation $[33,34]$. Since $P_{p A}$ and $P_{p D}$ initiate transcription in opposite directions, the distal portions of UASD and UAS $\mathrm{U}_{\mathrm{A}}$ overlap by $7 \mathrm{nt}$ in the center (Figure $2 \mathrm{~b}$ ). In vitro studies by protein affinity chromatography yield that GvpE interacts with any TFB and TBP tested [26,35]. Binding constants between GvpE and the various general transcription factors have not been determined. Putative differences in the GvpE-TFB and/or GvpE-TBP affinities might cause alterations in the environment-dependent regulation of $g v p$ gene expression. GvpE could stimulate their binding at $P_{p A}$ and $P_{p D}$ to enhance the transcription initiation.

a

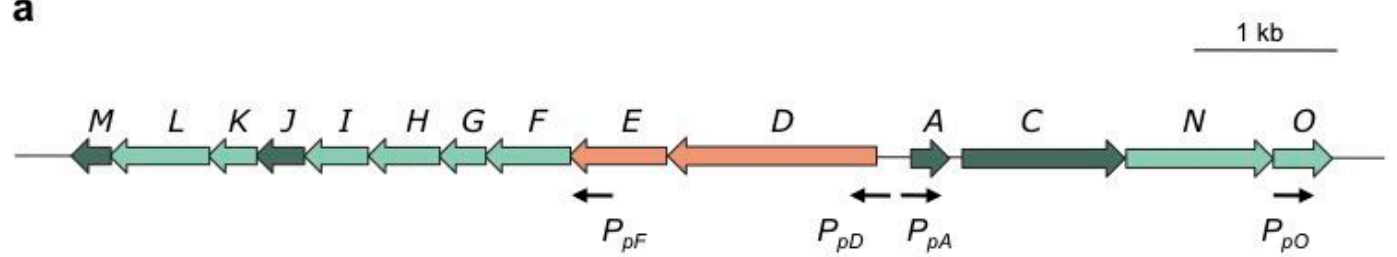

b

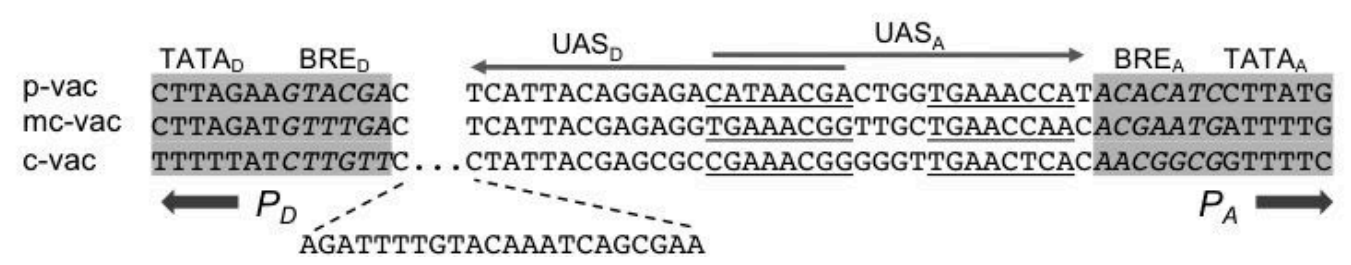

Figure 2. Arrangement of gvp genes in p-vac of Hbt. salinarum PHH1 (a) and a comparison of the intergenic regions separating $P_{D}$ and $P_{A}$ (b). (a) The arrows depicting genes are colored as follows: dark green, encoding structural proteins of the A-J-M family and GvpC; light green, encoding accessory Gvp; red, encoding regulator proteins. Black arrows mark the start sites of transcription. (b) Comparison of the intergenic regions separating $P_{A}$ and $P_{D}$ in p-, mc- and c-vac. A 22-nt insertion occurs in c-vac adjacent to BRED. The 20-nt sequence required for GvpE-mediated activation is underlined (8-nt elements separated by $4 \mathrm{nt}$ of unimportant sequences) in the case of $\mathrm{UAS}_{\mathrm{A}}$ and marked by an arrow. Similar activation elements are found with $\mathrm{UAS}_{\mathrm{D}}$, pointing in the opposite direction. The TATA-box and BRE sequences (italics) are shaded in grey.

The presence of GvpE leads to a fast and strong activation of $P_{p A}$ and $P_{p D}$ under standard growth conditions, but as soon as GvpD appears, the activation is reduced (Figure 3). GvpD and GvpE are able to interact, and the presence of GvpD leads to an almost undetectable amount of GvpE, as determined by western analysis [36]. The reduction in the amount of GvpE was quantified using the green fluorescent protein smGFP fused to the N-terminus of GvpE [37]. The amount of GFP-GvpE is more than $60 \%$ reduced in the presence of GvpD. The fact that a reduction in the amount of GvpE is not observed in the presence of the repression defective GvpDMut6 mutant underlines that a functional GvpD is required for this process [37].

The repressing function of GvpD was initially observed in $\Delta \mathrm{D}$ transformants carrying the mc-vac region of $H f x$. mediterranei with a 918-bp deletion in the gvpD reading frame ( $\Delta \mathrm{D}$ construct) [38]. Hfx. volcanii $\Delta \mathrm{D}$ transformants are filled with numerous gas vesicles, turning the flat and disc-shaped cells into spheres, and the presence of GvpD in $\Delta \mathrm{D}+\mathrm{D}$ transformants reduces the amount of gas vesicles to the wild-type level. 
GvpD oligomerizes in solution and exhibits similarities to the large family of AAA+ ATPase proteins by possessing a Walker I and II motif to bind ATP and an arginine-rich region [39]. Both motifs are required for the GvpD-induced breakdown of GvpE. The repression defective GvpDMut6 mentioned above carries mutations in the Walker motif, underlining that nucleotide binding is important for the GvpD function [40]. A second arginine-rich region close to the C-terminus of GvpD is also involved in repression, since an alteration of this $494 \mathrm{RRR} 496$ sequence to three alanine residues yields the super-repressor, GvpD3-AAA [40]. In presence of GvpD3-AAA, the fluorescence of GFP-GvpE is reduced to $20 \%$ of the original fluorescence in $H f x$. volcanii transformants [37].

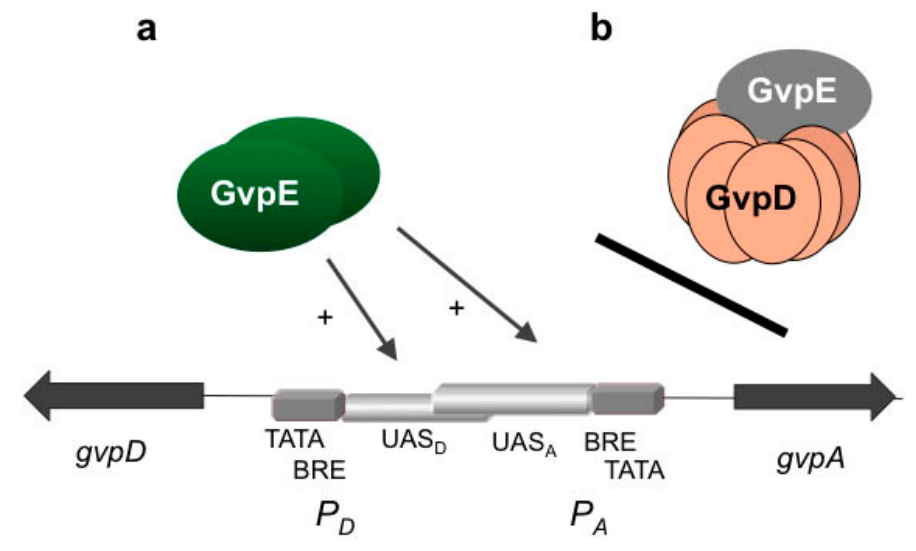

Figure 3. Activation of $P_{A}-P_{D}$ by GvpE (a) and repression by GvpD (b). Schematic representation of the region between $g v p A$ and $g v p D$ and the two oppositely-oriented promoters $P_{A}$ and $P_{D}$. TATA-box and BRE are shown in grey, and the two UAS elements are partly overlapping in the center in light grey. The reading frames $g v p D$ and $g v p A$ are represented by dark arrows. (a) Activation of transcription by GvpE should involve binding of GvpE, presumably as a dimer, at the respective UAS element and recruitment of TFB, TBP and of the RNA polymerase. (b) In the presence of GvpD, the interaction of GvpEGvpD leads to a strong reduction in the amount of GvpE and the repression of gas vesicle formation.

The additional promoters, $P_{p F}$ and $P_{p O}$, of the p-vac region are independent of GvpE and drive the synthesis of accessory Gvp proteins [33]. $P_{p O}$ yields the essential GvpO throughout growth, but the function of this protein is not yet known. $P_{p F}$ is active during the exponential and early stationary growth phase and leads to minor amounts of the p-gvpFGHIJKLM transcript [41]. The transcript start occurs 177-nt within the $g v p E$ reading frame. Since the AUG start codon of $g v p F$ occurs 8-nt within $g v p E$, the p-gvpF-M transcript contains a 169-nt 5'-UTR. The amounts of the accessory proteins, GvpF through GvpM, are much lower compared to GvpA and GvpC, and except for GvpI and $\mathrm{GvpH}$, all of them are required for the formation of the gas vesicle wall [42].

A very similar GvpE-mediated activation of $P_{A}$ and $P_{D}$ occurs in the mc-vac region, whereas in the case of c-vac, $P_{c A}$ is the only promoter induced by GvpE. $P_{c D}$ incurred a 22-bp insertion adjacent to BRE, enlarging the distance to $\mathrm{UAS}_{\mathrm{D}}$ and, thus, abolishing GvpE-activation (Figure 2b) $[6,43]$. The close distance of UAS-BRE is essential for the activation [34]. The basal activity of $P_{c D}$ is very weak and 
yields minor amounts of c-gvpDEFGHIJKLM transcripts in late exponential growth. Additional promoters are neither found in mc-vac nor in c-vac.

All of these analyses demonstrate the importance of $P_{A}$ and $P_{D}$ for the formation of gas vesicles. The transcriptional activation by GvpE leads to the large amounts of the major gas vesicle structural protein, GvpA. The amount of the activator, GvpE, is reduced in the presence of GvpD and, thus, also, the production of gas vesicles. To investigate the function of the GvpE/GvpD regulatory system in more detail, crystal structures of both proteins are required. Furthermore, additional mutants inactive in regulation will be useful to pinpoint other regions important for the regulatory functions.

\section{Environmental Factors Influencing Transcription}

Oxygen availability, temperature, salt concentration and carbon sources all influence the formation of gas vesicles in Haloarchaea [18,26,44-46]. Growth under anoxic conditions is supported by nitrate respiration (Hfx. mediterranei) or arginine fermentation in the case of Hbt. salinarum. The amounts of the $g v p A C N O$ and $g v p D-M$ transcripts are 10-fold reduced in both species under anoxic conditions, and only a few small gas vesicles are formed [45] (Table 3). Hfx. volcanii mc-vac transformants grown by nitrate respiration also show a 10 -fold reduced expression. It is interesting to note that aerobic $\Delta \mathrm{D}$ transformants (i.e., mc-vac with a 918-bp deletion in mc-gvpD) are filled with numerous gas vesicles, but lack these structures completely when grown under anoxic conditions. Thus, the absence of gas vesicles under anoxic conditions is independent of the repressing protein, GvpD. The extremely large amount of mc-gvpA transcripts in $\triangle \mathrm{D}$ transformants is 10 -fold reduced under these conditions, but still large compared to the wild-type. Furthermore, GvpA is present in relatively large amounts in $\Delta \mathrm{D}$ transformants, implying that the gas vesicle formation is inhibited at the level of assembly [45]. The lower amount of ATP produced under anoxic conditions and/or the smaller amounts of accessory proteins might restrict the formation of gas vesicles under these conditions. However, Hbt. salinarum PHH1 and NRC-1 grown by anaerobic respiration with dimethylsulfoxide (DMSO) or trimethylamine$\mathrm{N}$-oxide (TMAO) as the terminal electron acceptor produce many gas vesicles, demonstrating that a lack of oxygen does not always lead to a reduced number of gas vesicles $[45,46]$.

The effect of temperature on gas vesicle formation was studied with Hbt. salinarum PHH1 and NRC-1 $[26,47]$. Heat shock conditions $\left(1 \mathrm{~h}\right.$ at $49{ }^{\circ} \mathrm{C}$ followed by $3 \mathrm{~h}$ at $56^{\circ} \mathrm{C}$ and subsequent growth at $37^{\circ} \mathrm{C}$ ) lead to an eight-fold reduced amount of p-gvp $A$ transcripts in PHH1, and the gas vesicle formation stops completely (Table 3). The p- $g v p A$ mRNA is rapidly lost during heat shock treatment [26]. A reduction in the $g v p E$ mRNA encoding the transcriptional activator, GvpE, might also contribute to the interruption of gas vesicle formation, as determined for NRC-1 [47]. In contrast, PHH4 is able to cope very well with heat shock conditions. A reduction in growth is not observed; nevertheless, the amount of c-gvpA drops significantly, and gas vesicle formation stops [26]. It is possible that the secondary structure of the $g v p A$ mRNA contributing to the stability of the transcript is destroyed under heat shock conditions. PHH1 and NRC-1 grown at the relatively cold temperature of $15{ }^{\circ} \mathrm{C}$ contain very large amounts of gas vesicles. A two-fold increase (PHH1) in the expression of p-gvpACNO was determined by quantitative RT-PCR [26], and a 1.8- to 8-fold increase of $g v p A C N O$ and a three-fold increase in $g v p D E$ expression were determined for NRC-1 by microarray analyses [47]. The higher transcription of the gvp gene clusters under cold conditions is exceptional, since most housekeeping genes of $\mathrm{Hbt}$. salinarum are downregulated at $15^{\circ} \mathrm{C}$. 
GvpE might activate transcription continuously, since the amount is not reduced. The interaction of GvpD and GvpE (resulting in the degradation of GvpE) might be disturbed or the proteases involved in the breakdown of $\mathrm{GvpE}$ are less functional at $15^{\circ} \mathrm{C}[26]$.

Table 3. Environmental factors influencing gas vesicle formation.

\begin{tabular}{|c|c|c|c|}
\hline $\begin{array}{c}\text { Environmental } \\
\text { Factors }\end{array}$ & Strains and Conditions & $\begin{array}{c}\text { Effect on } \\
\text { Vac } \\
\end{array}$ & Effect on $g v p$ Transcription \\
\hline \multirow{4}{*}{ Anaerobiosis } & Hbt. salinarum p-vac & & \\
\hline & + arginine & $\mathrm{Vac}^{-}$ & 10-fold reduced compared to oxic growth \\
\hline & +TMAO & $\mathrm{Vac}^{+}$ & not altered compared to oxic growth \\
\hline & $+\mathrm{DMSO}$ & $\mathrm{Vac}^{+}$ & not altered compared to oxic growth \\
\hline \multirow{3}{*}{ Temperature } & Hbt. salinarum p-vac & & \\
\hline & $15^{\circ} \mathrm{C}$ & $\mathrm{Vac}^{++}$ & 2-fold increase compared to $37^{\circ} \mathrm{C}$ \\
\hline & heat shock & $\mathrm{Vac}^{-}$ & 8-fold reduced compared to $37^{\circ} \mathrm{C}$ \\
\hline \multirow{3}{*}{$\begin{array}{c}\text { Salt } \\
\text { concentration }\end{array}$} & Hfx. mediterranei mc-vac & & \\
\hline & $15 \%$ salt & $\mathrm{Vac}^{-}$ & - \\
\hline & $25 \%$ salt & $\mathrm{Vac}^{+}$ & 7-fold increase compared to $15 \%$ salt \\
\hline \multirow{4}{*}{ Glucose } & Hfx. mediterranei mc-vac & & \\
\hline & $50 \mathrm{mM}$ & $\mathrm{Vac}^{ \pm}$ & - \\
\hline & $100 \mathrm{mM}$ & $\mathrm{Vac}^{-}$ & 10-fold reduced compared to standard \\
\hline & $200 \mathrm{mM}$ & $\mathrm{Vac}^{-}$ & - \\
\hline
\end{tabular}

The sodium chloride concentration of the medium influences the gas vesicle formation of the moderately halophilic $H f x$. mediterranei. Gas vesicles are only formed when this species is grown in $17 \%-30 \%(\mathrm{w} / \mathrm{v})$ salt media, whereas cells grown in $15 \%$ salt media are $\mathrm{Vac}^{-}$(Table 3 ). The amount of the mc-gvp $A$ transcripts is seven-fold enhanced in cells grown in $25 \%$-salt compared to the $15 \%$-salt culture [18]. Glucose also influences the $P_{m c A}$ promoter activity, since the addition of 50, 100 or $200 \mathrm{mM}$ glucose results in a 10-fold reduction of the basal activity of $P_{m c A}$, whereas the activity of the promoter of the housekeeping ferredoxin gene, $P_{f d x}$, is almost unaffected [44]. A complete inhibition of gas vesicle formation is observed at glucose concentrations above $100 \mathrm{mM}$. Maltose and sucrose impose a similar effect, whereas xylose, arabinose, lactose, pyruvate and 2-deoxy-glucose have no influence [44]. Also in this case, $\Delta \mathrm{D}$ transformants lack gas vesicles in the presence of glucose, demonstrating that the repressing protein, GvpD, is not involved. The function of GvpD as a glucose sensor is thus excluded.

In summary, the GvpE/GvpD regulatory system is often not involved in the transfer of environmental signals to the respective vac region. It appears that both regulatory proteins are mainly required to enhance the gas vesicle formation under standard conditions in Hbt. salinarum and Hfx. mediterranei. Since most gas vesicle gene clusters of other Haloarchaea lack $g v p D E$, the impact of GvpD and GvpE on $g v p$ gene expression is confined to a few species [10].

\section{Relevance of 5'-UTR and Shine-Dalgarno Sequence for Translation}

The transcription of $\mathrm{p}$-vac starts with the p-gvpFGHIJKLM in the early exponential growth phase, followed by $\mathrm{p}-g v p D E, \mathrm{p}-g v p A C N O$ and $p$-gvpO. Except for $\mathrm{p}-g v p O$, all transcripts contain a 5'-untranslated region (5'-UTR), with sizes of 20-nt (p-gvpACNO), 72-nt (p-gvpDE) and 169-nt 
(p-gvpFGHIJKLM). With the exception of p-gvpA and p-gvpO, all reading frames are preceded by a putative Shine-Dalgarno (SD) sequence (GGAGGUCA) that appears at a distance of 5 to $13 \mathrm{nt}$ of the AUG start codon [48]. The SD element is complementary to a sequence found near the 3 ' end of the small ribosomal subunit rRNA of Hbt. salinarum. In bacteria, SD sequences facilitate the transcript recognition at the $30 \mathrm{~S}$ ribosomal subunit, whereas in Archaea, their importance is under debate.

An almost perfect SD sequence is found $7 \mathrm{nt}$ upstream of the AUG of the p-gvpH reading frame. A 4-nt scanning mutagenesis of this region uncovered that mutations in the SD sequence lead to a $5 \%-50 \%$ reduction in translation, as quantified using bgaH encoding a haloarchaeal $\beta$-galactosidase as the reporter $[48,49]$. However, even a complete alteration of this element leads to a residual $\mathrm{BgaH}$ activity of $20 \%$ compared to the wild-type. Altering the spacing of the SD element of p-gvpH with respect to the AUG start codon yields a good translation with distances of 4 to $10 \mathrm{nt}$, but a spacing of only $1 \mathrm{nt}$ results in the loss of translation. These observations suggest that the SD sequence supports translation, but does not strictly control the expression of a reading frame [48]. These results differ from the analysis of SD sequences in the hyperthermophilic archaeon, Sulfolobus solfataricus, where single nucleotide alterations in the SD sequence completely prevent translation in vitro [50]. Another investigation of a putative SD sequence in the 5'-UTR of the single sod gene of $H f x$. volcanii shows that partial mutations or even a complete removal of the SD sequence has no effect on the translation efficiency, implying that this sequence has no function [51]. Taking the massive acquisition of bacterial genes in the haloarchaeal founder organism into account [1,2], the SD sequences might be remnants of bacterial origin with little or no influence on the expression of single genes. However, it is remarkable that genes organized in operons, such as in the vac regions, usually contain SD sequences that influence translation, as shown for p-gvpH and p-gvpG [48].

A much larger influence on translation is even achieved when the 5'-UTR is lacking. Bioinformatic analyses predict that $30 \%$ of the haloarchaeal genes are transcribed as leaderless mRNA, including the ferredoxin transcript starting $1 \mathrm{nt}$ upstream of the AUG start codon [52]. Ferredoxin constitutes $2 \%$ of the total proteins in Hbt. salinarum, and the $f d x$ gene is strongly transcribed and efficiently translated. The haloarchaeal expression vector pJAS35 is based on the strong expression of the leaderless transcripts under $P_{f d x}$ promoter control [53]. In the case of the p-vac region, a deletion of the entire 5'-UTR of p-gvpH (i.e., creating a leaderless transcript) results in a 15-fold enhanced translation [48]. Moreover, all leaderless transcripts constructed for $\mathrm{p}$-vac yield a stronger expression compared to their leader-containing counterparts. These results imply that 5'-UTRs regulate gene expression by reducing the translation efficiency. The 5'- or 3'-UTRs of the haloarchaeal transcripts often form secondary structures that stabilize the mRNA (as seen with the p-gvpA transcript) or these regions offer binding sites of proteins or small regulatory RNAs, influencing translation initiation. The exploration of the regulatory potential of 5'- and 3'-UTRs is still ongoing and will certainly yield further information.

\section{Effect of Deletions and Overexpression of Single gvp Genes on Gas Vesicle Formation}

The importance of the various Gvp proteins for gas vesicle formation was deduced from $H f x$. volcanii transformants carrying $\mathrm{p}$-vac constructs that incurred a deletion of a single gvp gene ( $\Delta \mathrm{X}$ constructs) and also from transformants containing p-vac plus an additional gvp gene overexpressed in pJAS35. The deletion analyses determined the eight genes, $g v p A, F, G, H, J, K, L, M$ and $O$, as essential for the 
synthesis of gas-filled compartments [42]. Deletion of p- $g v p D E$ results in minor amounts of gas vesicles, whereas a deletion of $g v p I, g v p H, g v p N$ or $g v p C$ leads to extremely long $(\Delta \mathrm{I})$, fragile $(\Delta \mathrm{H}, \Delta \mathrm{C})$, small $(\Delta \mathrm{N})$ or large and egg-shaped $(\Delta \mathrm{C})$ gas vesicles. Complementation of such $\Delta \mathrm{X}$ transformants by the missing gvp gene again results in gas vesicles similar to Hbt. salinarum PHH1 [42]. An additional study has been performed with the gvpl gene cluster of Hbt. salinarum NRC-1 using insertions of a kanamycin-resistance cassette ( $\kappa$-element) in various gvp genes generated in Escherichia coli [54]. The effect of this linker-scanning mutagenesis on gas vesicle formation was studied in a pNRC100-deficient $H b t$. salinarum NRC-1 variant still containing a partially expressed gvp2 gene cluster. The results of the two studies (deletions versus insertions) differ in six out of 14 cases, and possible reasons have been discussed earlier [55]. They include also polar effects of the $\kappa$-insertion on the expression of $g v p$ genes located downstream of the integration site.

An overexpression of $g v p F, G, H, I, J, K, L$ or $M$ in the presence of p-vac does not affect gas vesicle formation, but the presence of large amounts of GvpG, GvpH or GvpM results in $\mathrm{Vac}^{-}$transformants [56]. Since p-vac + GHIJKLM ${ }^{\text {ex }}$ transformants ( $g v p G-M$ inserted in the expression vector pJAS35) produce gas vesicles similar to the wild-type, a balanced amount of the accessory proteins is obviously required for gas vesicle assembly. It is possible that GvpG, GvpH or GvpM interact with other essential Gvp proteins produced in minor amounts by $\mathrm{p}$-vac, thus diminishing the amount(s) of the essential partner protein(s) required for gas vesicle assembly. GvpG and GvpH are soluble, but the hydrophobic GvpM forms aggregate when produced in large amounts, easily seen with GvpM fusions to the green fluorescent smGFP. Such GvpM-GFP (MGFP) transformants containing one to two large fluorescent foci per cell. In contrast, cells containing $\mathrm{H}_{\mathrm{GFP}}$ or LGFP are fully fluorescent [57]. Together with GvpJ and GvpA, GvpM belongs to the A-J-M family of hydrophobic Gvp proteins. P-vac + MX ${ }^{\text {ex }}$ transformants ( $\mathrm{X}=\mathrm{G}, \mathrm{H}, \mathrm{J}$ or $\mathrm{L}$ ) demonstrate that $\mathrm{GvpH}$, GvpJ or GvpL are able to neutralize the inhibitor effect of GvpM, whereas GvpG is unable to do so. Protein affinity chromatography confirms that GvpM interacts with GvpH, GvpJ or GvpL, but not with GvpG, supporting the hypothesis that M-H, M-J and M-L

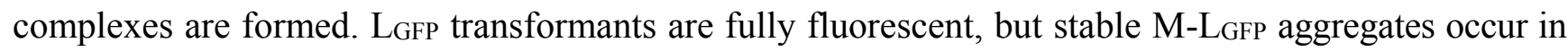
the presence of GvpM. In contrast, M-H aggregates are neither observed in $\mathrm{H}_{\mathrm{GFP}} \mathrm{M}$ nor in H-MGFP transformants carrying GFP fused to the C-terminus of GvpH ( $\left.\mathrm{H}_{\mathrm{GFP}}\right)$ or GvpM (MGFP) [57]. The product could be too small to be visualized as fluorescence foci in the cells. GvpH might prevent the unspecific aggregation of GvpM by keeping this protein "soluble" and, thus, useful for incorporation in the gas vesicle wall. Similar analyses with other accessory Gvp proteins will unravel additional complexes that might occur during gas vesicle assembly.

\section{Gas Vesicle Wall and Mutations Affecting the Shape}

GvpA constitutes the almost crystalline gas vesicle wall, forming a helix of low pitch seen as ribs running perpendicular to the long axis by transmission electron microscopy [58,59]. The gas vesicle wall is difficult to disaggregate, and the protein constituents are difficult to analyze. Immunological methods and MALDI-TOF mass spectrometry indicate that with the exception of GvpK, all Gvp proteins are present $[60,61]$. The sequence of the $8-\mathrm{kDa}$ GvpA is highly conserved between archaeal and also bacterial gas vesicle producers (see Figure 4), and differences occur mainly near the N- and C-terminus. GvpA is not post-translationally modified, as demonstrated by protein sequencing and MALDI-TOF mass 
spectrometry [59,61]. A crystal structure of GvpA is not available due to its hydrophobic nature and high tendency to aggregate. The secondary structure prediction of GvpA suggests a coil- $\alpha-\beta-\beta-\alpha$-coil fold (Figure 5a) [62,63]. Solid-state NMR and Fourier transform infrared spectroscopy (FTIR) with isolated gas vesicles indicates anti-parallel $\beta$-sheets, and $\mathrm{X}$-ray analyses and atomic force microscopy imply that the $\beta$-strands of GvpA are tilted in the ribs at an angle of $54^{\circ}[59,62,64]$. The C-terminal portion of GvpA is exposed to the outside of the gas vesicles, since a trypsin site and several endopeptidase GluC sites are accessible here, whereas other portions of GvpA are protected [61].

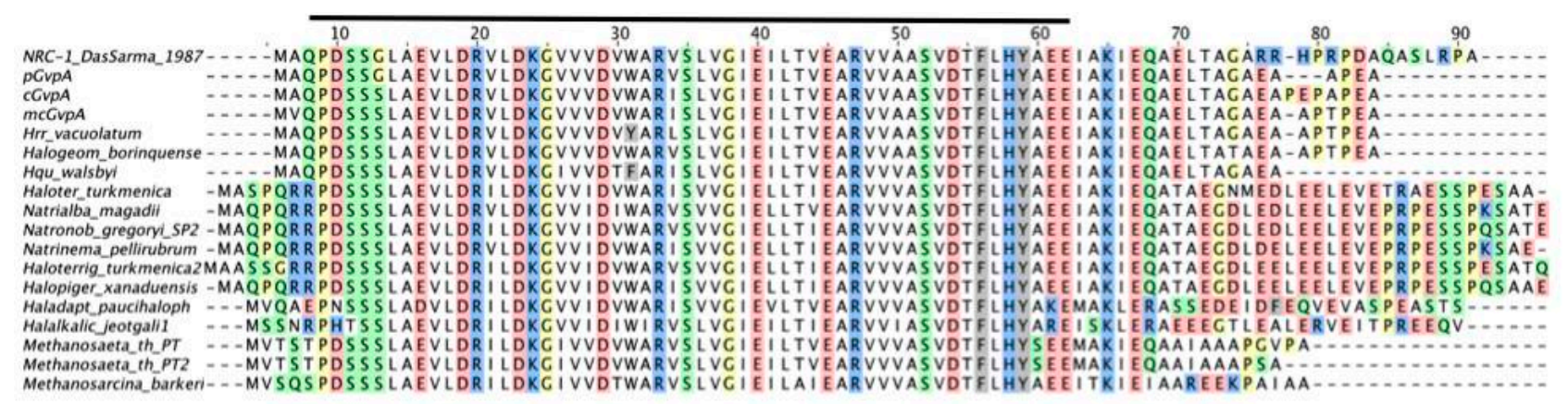

Figure 4. Sequence alignment of GvpA proteins derived from Haloarchaea and methanogens. Identical amino acid residues are highlighted in the following colors: red, negatively charged; blue, positively charged; green, polar, uncharged; yellow, small and variable; grey, aromatic; white, non-polar residues. The bar on top marks the highly conserved central 51 amino acids. The difference in the C-terminus of GvpA ( $g v p 1, \mathrm{NRC}-1)$ to the sequence of pGvpA (p-vac, PHH1) is due to a missing G nucleotide close to the 3'-terminus of $g v p A$ in gvp1. pGvpA and cGvpA are derived from Hbt. salinarum PHH1 and mcGvpA from $H f x$. mediterranei.

A 3D model was derived from a high-performance de novo modelling of mcGvpA [63], and the model was confirmed for the almost identical GvpA of Hbt. salinarum NRC-1 [65]. The hydrophobic $\beta$-sheet portion most likely faces the gas phase and prevents the precipitation of water molecules entering the gas-filled core. A more hydrophilic portion, including the $\alpha$-helix $\mathrm{H} 2$, constitutes the outer surface facing the cytoplasm. Single amino acid alterations in GvpA, studied in $\Delta \mathrm{A}+\mathrm{A}$ mut transformants for their ability to form gas vesicles, pinpoint essential amino acid positions. Construct $\Delta \mathrm{A}$ contains all $\mathrm{p}$-vac gvp genes, except for $g v p A$, and can be complemented by gvpA wild-type or mutant genes $[42,63]$. Some of the GvpA mutations abolish the formation of gas vesicles, i.e., single alanine substitutions of the polar amino acids in $\alpha$-helix H1 (Figure 5b,c), whereas other mutations have no effect on gas vesicle formation [63]. Polar residues at the surface might form salt bridges to connect GvpA-GvpA molecules or GvpA with accessory GvpX in the wall. Some GvpA mutants yield extremely long and thin gas vesicles in transformants (GvpA $\mathrm{A}_{\mathrm{I} 4 \mathrm{M}}$ and others) or mini gas vesicles (GvpA $\mathrm{A}_{60 \mathrm{~A}}$ and others) that are never or only slowly enlarged [63]. The diversity of gas vesicle structures shows the dependency of the shape on the respective GvpA mutant. Such shape variants are useful to investigate the architecture of this nanocompartment. 


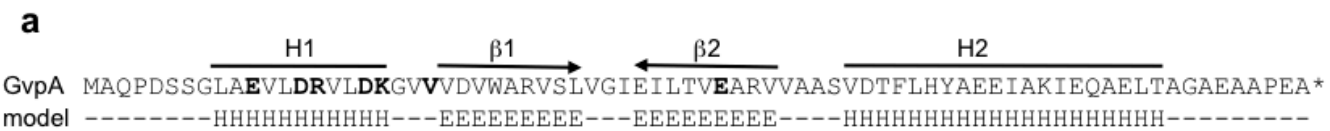

b

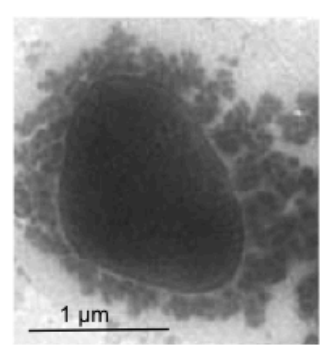

c

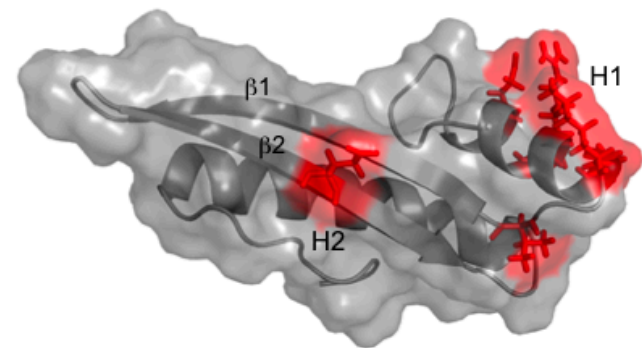

Figure 5. Amino acid sequence of GvpA and the structure derived from the in silico modelling. (a) Amino acid sequence of pGvpA and the proposed 2D structure (model). $\mathrm{H}$ denotes $\alpha$-helices and $\mathrm{E} \beta$-strands. The $\alpha$-helices, $\mathrm{H} 1$ and $\mathrm{H} 2$, and the anti-parallel $\beta$-strands are indicated on top. (b) Electron micrograph of a $\mathrm{Vac}^{-} \Delta \mathrm{A}+\mathrm{A}$ mut transformant, showing that gas-filled compartments are indeed lacking in such mutants. (c) Structure of GvpA, highlighting some positions of ala-substitutions leading to gas vesicle negative $\Delta \mathrm{A}+\mathrm{Amut}$ transformants [63]. The respective single amino acids that are altered are shown in bold in (a).

\section{Application of Gas Vesicles}

Gas vesicles nanostructures are objects for special applications in biomedical research. The almost crystalline gas vesicle wall provides the structural rigidity to maintain a hollow gas-filled core that is useful as an ultrasonic contrast agent in biomedical research and clinical diagnostics [66]. In contrast to the lipid- or protein-stabilized micro-bubbles, gas vesicles produce a stable ultrasound contrast and provide a much larger mechanical response. The acoustic scattering signal can be also silenced using ultrasound amplitudes exceeding the critical collapse pressure of the gas vesicles.

Gas vesicles are also applied as reporters for hyperpolarized xenon magnetic resonance imaging (MRI) and enable non-invasive observation of the anatomy and function of organisms [67]. They are capable of chemical exchange saturation transfer interactions. Filled with hyperpolarized ${ }^{129} \mathrm{Xe}$, they allow chemically-amplified gas vesicle detection at picomolar concentrations. Functionalized gas vesicles carrying surface-attached streptavidin antibodies against the HER2 receptor are able to label an HER2-expressing breast cancer cell line, so that these cells are easily distinguishable from others by MRI [67].

In addition, gas vesicles are an effective antigen display system based on a fusion of the peptide of interest to the surface protein, GvpC. The expression of such gvpC-fusions in Hbt. salinarum yields recombinant gas vesicles displaying these peptides on the surface. The recombinant gas vesicles are easy to isolate by lysis of the haloarchaeal cells and repeated centrifugally accelerated flotation. They are self-adjuvanting, and the antigenic epitopes displayed on the surface stimulate the immune system. Gas vesicles have been used to expose different SIV peptides (Tat, Rev, NefI) [68,69], outer membrane proteins of the pathogen, Chlamydia trachomatis [70], or portions of the Salmonella SopB antigen [71]. The antiserum raised against the Chlamydia proteins is useful to detect the pathogen in sera of 
Chlamydia-positive patients. The Salmonella protein, SopB, is injected during the pathogenesis of typhoid, and mice boosted with SopB gas vesicles elicit a protective response to Salmonella infection. Such recombinant gas vesicles will be further developed as improved vaccines [71].

\section{Conclusions}

Gas vesicles produced by several microorganisms, including Haloarchaea, have been investigated for a long time. These nanocompartments are easy to isolate, but difficult to disaggregate to investigate the protein constituents of the protein wall. The genes encoding these structures are used as model systems to explore archaeal gene regulation and signal transduction at the level of transcription, translation and protein networks. Current research aims to resolve the structure of the major gas vesicle protein, GvpA, by solid-state NMR, and high resolution cryo-electron tomography on isolated gas vesicles is used to determine the structure of GvpA in the gas vesicle wall. Mutants of GvpA and also of the accessory Gvp support and complement these investigations. Such mutants are also helpful to unravel gas vesicle genesis in vivo. More recently, interesting applications of gas vesicles have emerged in biomedical research, taking advantage of the stability of gas vesicles and exploiting them, for instance, as ultrasonic contrast agents.

\section{Acknowledgments}

The author thanks Sabrina Fröls and Arnulf Kletzin for fruitful discussions and Arnulf Kletzin for the sequence alignment presented in Figure 3. Karin Faist is thanked for the electron micrographs. This research was supported by grants from the German Research Foundation (DFG; PF165/10-1,2 and PF165/12-1).

\section{Conflict of Interests}

The author declares no conflict of interest.

\section{References}

1. Nelson-Sathi, S.; Dagan, T.; Landan, G.; Janssen, A.; Steel, M.; McInerney, J.O.; Deppenmeier, U.; Martin, W.F. Acquisition of 1000 eubacterial genes physiologically transformed a methanogen at the origin of haloarchaea. Proc. Natl. Acad. Sci. USA 2012, 109, 20537-20542.

2. Nelson-Sathi, S.; Sousa, F.L.; Roettger, M.; Lozada-Chavez, N.; Thiergart, T.; Janssen, A.; Bryant, D.; Landan, G.; Schönheit, P.; Siebers, B.; et al. Origins of major archaeal clades correspond to gene acquisitions from bacteria. Nature 2015, 517, 77-80.

3. Klebahn, H. Gasvakuolen, ein Bestandteil der Zellen der wasserblütenbildenden Phycochromaceen. Flora (Jena) 1895, 80, 241-282. (In German)

4. Oesterhelt, D. The structure and mechanism of the family of retinal proteins from halophilic archaea. Curr. Opin. Struc. Biol. 1998, 8, 489-500.

5. Atamna-Ismaeel, N.; Sabehi, G.; Sharon, I.; Witzel, K.P.; Labrenz, M.; Jurgens, K.; Barkay, T.; Stomp, M.; Huisman, J.; Beja, O. Widespread distribution of proteorhodopsins in freshwater and brackish ecosystems. ISME J. 2008, 2, 656-662. 
6. $\quad$ Englert, C.; Krüger, K.; Offner, S.; Pfeifer, F. Three different but related gene clusters encoding gas vesicles in halophilic archaea. J. Mol. Biol. 1992, 227, 586-592.

7. Mayr, A.; Pfeifer, F. The characterization of the nv-gvpACNOFGH gene cluster involved in gas vesicle formation in Natronobacterium vacuolatum. Arch. Microbiol. 1997, 168, 24-32.

8. Bolhuis, H.; te Poele, E.M.; Rodriguez-Valera, F. Isolation and cultivation of Walsby's square archaeon. Environ. Microbiol. 2004, 6, 1287-1291.

9. Burns, D.G.; Camakaris, H.M.; Janssen, P.H.; Dyall-Smith, M.L. Cultivation of Walsby's square haloarchaeon. FEMS Microbiol. Lett. 2004, 238, 469-473.

10. Pfeifer, F. Distribution, formation and regulation of gas vesicles. Nat. Rev. Microbiol. 2012, 10, $705-715$.

11. DasSarma, S.; Damerval, T.; Jones, J.G.; Tandeau de Marsac, N. A plasmid-encoded gas vesicle protein gene in a halophilic archaebacterium. Mol. Microbiol. 1987, 1, 365-370.

12. Horne, M.; Pfeifer, F. Expression of two gas vacuole protein genes in Halobacterium halobium and other related species. Mol. Gen. Genet. 1989, 218, 437-444.

13. Horne, M.; Englert, C.; Wimmer, C.; Pfeifer, F. A DNA region of 9 kbp contains all genes necessary for gas vesicle synthesis in halophilic archaebacteria. Mol. Microbiol. 1991, 5, 1159-1174.

14. Horne, M.; Englert, C.; Pfeifer, F. Two genes encoding gas vacuole proteins in Halobacterium halobium. Mol. Gen. Genet. 1988, 213, 459-464.

15. Blaseio, U.; Pfeifer, F. Transformation of Halobacterium halobium: Development of vectors and investigation of gas vesicle synthesis. Proc. Natl. Acad. Sci. USA 1990, 87, 6772-6776.

16. Pfeiffer, F.; Schuster, S.C.; Broicher, A.; Falb, M.; Palm, P.; Rodewald, K.; Ruepp, A.; Soppa, J.; Tittor, J.; Oesterhelt, D. Evolution in the laboratory: The genome of Halobacterium salinarum strain R1 compared to that of strain NRC-1. Genomics 2008, 91, 335-346.

17. DasSarma, S. Identification and analysis of the gas vesicle gene cluster on an unstable plasmid of Halobacterium halobium. Experientia 1993, 49, 482-486.

18. Englert, C.; Horne, M.; Pfeifer, F. Expression of the major gas vesicle protein gene in the halophilic archaebacterium Haloferax mediterranei is modulated by salt. Mol. Gen. Genet. 1990, 222, 225-232.

19. Pfeifer, F.; Weidinger, G.; Goebel, W. Genetic variability in Halobacterium halobium. J. Bacteriol. 1981, 145, 375-381.

20. DasSarma, S. Mechanisms of genetic variability in Halobacterium halobium: The purple membrane and gas vesicle mutations. Can. J. Microbiol. 1989, 35, 65-72.

21. Ng, W.L.; Kothakota, S.; DasSarma, S. Structure of the gas vesicle plasmid in Halobacterium halobium: Inversion isomers, inverted repeats, and insertion sequences. J. Bacteriol. 1991, 173, 1958-1964.

22. Ng, W.V.; Kennedy, S.P.; Mahairas, G.G.; Berquist, B.; Pan, M.; Shukla, H.D.; Lasky, S.R.; Baliga, N.S.; Thorsson, V.; Sbrogna, J.; et al. Genome sequence of Halobacterium species NRC-1. Proc. Natl. Acad. Sci. USA 2000, 97, 12176-12181.

23. Pfeifer, F.; Blaseio, U.; Horne, M. Genome structure of Halobacterium halobium: Plasmid dynamics in gas vacuole deficient mutants. Can. J. Microbiol. 1989, 35, 96-100.

24. Krüger, K.; Pfeifer, F. Transcript analysis of the c-vac region and differential synthesis of the two regulatory gas vesicle proteins GvpG and GvpE in Halobacterium salinarium PHH4. J. Bacteriol. 1996, 178, 4012-4019. 
25. Teufel, K.; Bleiholder, A.; Griesbach, T.; Pfeifer, F. Variations in the multiple tbp genes in different Halobacterium salinarum strains and their expression during growth. Arch. Microbiol. 2008, 190, 309-318.

26. Bleiholder, A.; Frommherz, R.; Teufel, K.; Pfeifer, F. Expression of multiple $t f b$ genes in different Halobacterium salinarum strains and interaction of $\mathrm{Tfb}$ with transcriptional activator GvpE. Arch. Microbiol. 2012, 194, 269-279.

27. Pfeifer, F.; Blaseio, U. Insertion elements and deletion formation in a halophilic archaebacterium. J. Bacteriol. 1989, 171, 5135-5140.

28. Turkarslan, S.; Reiss, D.J.; Gibbins, G.; Su, W.L.; Pan, M.; Bare, J.C.; Plaisier, C.L.; Baliga, N.S. Niche adaptation by expansion and reprogramming of general transcription factors. Mol. Syst. Biol. 2011, 7, doi:10.1038/msb.2011.87.

29. Ebert, K.; Goebel, W.; Pfeifer, F. Homologies between heterogeneous extrachromosomal DNA populations of Halobacterium halobium and four new isolates. Mol. Gen. Genet. 1984, 194, 91-97.

30. Gregor, D.; Pfeifer, F. Use of a halobacterial bgaH reporter gene to analyse the regulation of gene expression in halophilic archaea. Microbiology 2001, 147, 1745-1754.

31. Jäger, A.; Samorski, R.; Pfeifer, F.; Klug, G. Individual gvp transcript segments in Haloferax mediterranei exhibit varying half-lives, which are differentially affected by salt concentration and growth phase. Nucleic Acids Res. 2002, 30, 5436-5443.

32. Plößer, P.; Pfeifer, F. A bZip protein from halophilic archaea: Structural features and dimer formation of cGvpE from Halobacterium salinarum. Mol. Microbiol. 2002, 45, 511-520.

33. Hofacker, A.; Schmitz, K.M.; Cichonczyk, A.; Sartorius-Neef, S.; Pfeifer, F. GvpE- and GvpD-mediated transcription regulation of the p-gvp genes encoding gas vesicles in Halobacterium salinarum. Microbiology 2004, 150, 1829-1838.

34. Bauer, M.; Marschaus, L.; Reuff, M.; Besche, V.; Sartorius-Neef, S.; Pfeifer, F. Overlapping activator sequences determined for two oppositely oriented promoters in halophilic archaea. Nucleic Acids Res. 2008, 36, 598-606.

35. Teufel, K.; Pfeifer, F. Interaction of transcription activator GvpE with TATA-box-binding proteins of Halobacterium salinarum. Arch. Microbiol. 2010, 192, 143-149.

36. Zimmermann, P.; Pfeifer, F. Regulation of the expression of gas vesicle genes in Haloferax mediterranei: Interaction of the two regulatory proteins GvpD and GvpE. Mol. Microbiol. 2003, 49, 783-794.

37. Schmidt, I.; Pfeifer, F. Use of GFP-GvpE fusions to quantify the GvpD-mediated reduction of the transcriptional activator GvpE in haloarchaea. Arch. Microbiol. 2013, 195, 403-412.

38. Englert, C.; Wanner, G.; Pfeifer, F. Functional analysis of the gas vesicle gene cluster of the halophilic archaeon Haloferax mediterranei defines the vac-region boundary and suggests a regulatory role for the gvpD gene or its product. Mol. Microbiol. 1992, 6, 3543-3550.

39. Scheuch, S.; Pfeifer, F. GvpD-induced breakdown of the transcriptional activator GvpE of halophilic archaea requires a functional p-loop and an arginine-rich region of GvpD. Microbiology 2007, 153, 947-958.

40. Pfeifer, F.; Zotzel, J.; Kurenbach, B.; Röder, R.; Zimmermann, P. A p-loop motif and two basic regions in the regulatory protein GvpD are important for the repression of gas vesicle formation in the archaeon Haloferax mediterranei. Microbiology 2001, 147, 63-73. 
41. Offner, S.; Pfeifer, F. Complementation studies with the gas vesicle-encoding p-vac region of Halobacterium salinarium PHH1 reveal a regulatory role for the p-gvpDE genes. Mol. Microbiol. 1995, 16, 9-19.

42. Offner, S.; Hofacker, A.; Wanner, G.; Pfeifer, F. Eight of fourteen gvp genes are sufficient for formation of gas vesicles in halophilic archaea. J. Bacteriol. 2000, 182, 4328-4336.

43. Marschaus, L.; Pfeifer, F. A dual promoter region with overlapping activator sequences drives the expression of gas vesicle protein genes in haloarchaea. Microbiology 2012, 158, 2815-2825.

44. Hechler, T.; Frech, M.; Pfeifer, F. Glucose inhibits the formation of gas vesicles in Haloferax volcanii transformants. Environ. Microbiol. 2008, 10, 20-30.

45. Hechler, T.; Pfeifer, F. Anaerobiosis inhibits gas vesicle formation in halophilic archaea. Mol. Microbiol. 2009, 71, 132-145.

46. DasSarma, P.; Zamora, R.C.; Müller, J.A.; DasSarma, S. Genome-wide responses of the model archaeon Halobacterium sp. strain NRC-1 to oxygen limitation. J. Bacteriol. 2012, 194, $5530-5537$.

47. Coker, J.A.; DasSarma, S. Genetic and transcriptomic analysis of transcription factor genes in the model halophilic archaeon: Coordinate action of TbpD and TfbA. BMC Genet. 2007, 8, doi:10.1186/ 1471-2156-8-61.

48. Sartorius-Neef, S.; Pfeifer, F. In vivo studies on putative Shine-Dalgarno sequences of the halophilic archaeon Halobacterium salinarum. Mol. Microbiol. 2004, 51, 579-588.

49. Holmes, M.L.; Scopes, R.K.; Moritz, R.L.; Simpson, R.J.; Englert, C.; Pfeifer, F.; Dyall-Smith, M.L. Purification and analysis of an extremely halophilic beta-galactosidase from Haloferax alicantei. Biochim. Biophys. Acta 1997, 1337, 276-286.

50. Condo, I.; Ciammaruconi, A.; Benelli, D.; Ruggero, D.; Londei, P. Cis-acting signals controlling translational initiation in the thermophilic archaeon Sulfolobus solfataricus. Mol. Microbiol. 1999, 34, 377-384.

51. Kramer, P.; Gäbel, K.; Pfeiffer, F.; Soppa, J. Haloferax volcanii, a prokaryotic species that does not use the Shine Dalgarno mechanism for translation initiation at 5'-UTRs. PloS One 2014, 9, doi:10.1371/journal.pone.0094979.

52. Pfeifer, F.; Griffig, J.; Oesterhelt, D. The $f d x$ gene encoding the [2Fe-2S] ferredoxin of Halobacterium salinarium (H. halobium). Mol. Gen. Genet. 1993, 239, 66-71.

53. Pfeifer, F.; Offner, S.; Krüger, K.; Ghahraman, P.; Englert, C. Transformation of halophilic archaea and investigation of gas vesicle synthesis. Syst. Appl. Microbiol. 1994, 16, 569-577.

54. DasSarma, S.; Arora, P.; Lin, F.; Molinari, E.; Yin, L.R. Wild-type gas vesicle formation requires at least ten genes in the gvp gene cluster of Halobacterium halobium plasmid pNRC100. J. Bacteriol. 1994, 176, 7646-7652.

55. Pfeifer, F.; Krüger, K.; Röder, R.; Mayr, A.; Ziesche, S.; Offner, S. Gas vesicle formation in halophilic archaea. Arch. Microbiol. 1997, 167, 259-268.

56. Tavlaridou, S.; Faist, K.; Weitzel, K.; Pfeifer, F. Effect of an overproduction of accessory Gvp proteins on gas vesicle formation in Haloferax volcanii. Extremophiles 2013, 17, 277-287.

57. Tavlaridou, S.; Winter, K.; Pfeifer, F. The accessory gas vesicle protein GvpM of haloarchaea and its interaction partners during gas vesicle formation. Extremophiles 2014, 18, 693-706. 
58. Offner, S.; Ziese, U.; Wanner, G.; Typke, D.; Pfeifer, F. Structural characteristics of halobacterial gas vesicles. Microbiology 1998, 144, 1331-1342.

59. Walsby, A.E. Gas vesicles. Microbiol Rev. 1994, 58, 94-144.

60. Shukla, H.D.; DasSarma, S. Complexity of gas vesicle biogenesis in Halobacterium sp. Strain NRC-1: Identification of five new proteins. J. Bacteriol. 2004, 186, 3182-3186.

61. Belenky, M.; Meyers, R.; Herzfeld, J. Subunit structure of gas vesicles: A MALDI-TOF mass spectrometry study. Biophys. J. 2004, 86, 499-505.

62. Sivertsen, A.C.; Bayro, M.J.; Belenky, M.; Griffin, R.G.; Herzfeld, J. Solid-state NMR characterization of gas vesicle structure. Biophys. J. 2010, 99, 1932-1939.

63. Strunk, T.; Hamacher, K.; Hoffgaard, F.; Engelhardt, H.; Zillig, M.D.; Faist, K.; Wenzel, W.; Pfeifer, F. Structural model of the gas vesicle protein GvpA and analysis of GvpA mutants in vivo. Mol. Microbiol. 2011, 81, 56-68.

64. Blaurock, A.E.; Wober, W. Structure of wall of Halobacterium halobium gas vesicles. J. Mol. Biol. 1976, 106, 871-888.

65. Ezzeldin, H.M.; Klauda, J.B.; Solares, S.D. Modeling of the major gas vesicle protein, GvpA: From protein sequence to vesicle wall structure. J. Struct. Biol. 2012, 179, 18-28.

66. Shapiro, M.G.; Goodwill, P.W.; Neogy, A.; Yin, M.; Foster, F.S.; Schaffer, D.V.; Conolly, S.M. Biogenic gas nanostructures as ultrasonic molecular reporters. Nat. Nanotechnol. 2014, 9, 311-316.

67. Shapiro, M.G.; Ramirez, R.M.; Sperling, L.J.; Sun, G.; Sun, J.; Pines, A.; Schaffer, D.V.; Bajaj, V.S. Genetically encoded reporters for hyperpolarized xenon magnetic resonance imaging. Nat. Chem. 2014, 6, 629-634.

68. Sremac, M.; Stuart, E.S. Recombinant gas vesicles from Halobacterium sp. displaying SIV peptides demonstrate biotechnology potential as a pathogen peptide delivery vehicle. BMC Biotechnol. 2008, 8, doi: 10.1186/1472-6750-8-9.

69. Sremac, M.; Stuart, E.S. SIVsm Tat, Rev, and Nef1: Functional characteristics of r-GV internalization on isotypes, cytokines, and intracellular degradation. BMC Biotechnol. 2010, 10, doi:10.1186/1472-6750-10-54.

70. Childs, T.S.; Webley, W.C. In vitro assessment of halobacterial gas vesicles as a Chlamydia vaccine display and delivery system. Vaccine 2012, 30, 5942-5948.

71. DasSarma, P.; Negi, V.D.; Balakrishnan, A.; Karan, R.; Barnes, S.; Ekulona, F.; Chakravortty, D.; DasSarma, S. Haloarchaeal gas vesicle nanoparticles displaying Salmonella SopB antigen reduce bacterial burden when administered with live attenuated bacteria. Vaccine 2014, 32, 4543-4549.

(C) 2015 by the author; licensee MDPI, Basel, Switzerland. This article is an open access article distributed under the terms and conditions of the Creative Commons Attribution license (http://creativecommons.org/licenses/by/4.0/). 